\title{
El batán de Abánades. Arqueología de la Edad Moderna en el alto Tajuña.
}

\section{Abánades's fulling mill. Archaeology of the Modern Age in the high Tajuña.}

Consuelo Vara Izquierdo y José Martínez Peñarroya

CASTRVM patrimonio histórico S.L.

jmp.castrum@gmail.com - consuvaiz@gmail.com

Recibido: 16-05-2012

Aceptado: 20-09-2013

\section{Resumen:}

Con motivo de la construcción de un complejo turístico en la localidad de Abánades (Guadalajara), hemos tenido ocasión de identificar y describir los restos de un ingenio hidráulico en la ribera del río Tajuña. Tras el análisis de la estructura mediante el método de "Arqueología de la Arquitectura" fechamos los restos del edificio originario entre mediados de los siglos XVIII y XIX además de adscribirlos como parte de un posible batán que citan las escasas fuentes históricas conservadas sobre la localidad.

Palabras clave: Abánades, provincia de Guadalajara, Arqueología de la Arquitectura, Arqueología Preventiva, Molinos y batanes.

\begin{abstract}
As a reason to construct a tourist complex in the town of Abánades (Guadalajara), we have been able to identify and describe the archaeological remains of an hydraulic device in the bank of the Tajuña river. Following the analysis of the structure through the method of "Archaeology of Architecture" we date the remains of the building native between the mid centuries of XVIII and XIX as well as assigning them as part of a possible fulling mill which quote the reduced historical sources conserved from the town.
\end{abstract}

Key Words: Abánades, Province of Guadalajara, Archeology of Architecture, Preventive Archeology, Mills and Fulling mills.

Las riberas de los ríos de la Península Ibérica guardan aún los restos de las primitivas industrias que se establecieron para aprovechar la fuerza motriz de sus aguas. Sin remontarnos a los ingenios construidos en épocas hispanorromana e hispanomusulmana, desde plena Edad Media se conocen una variada suerte de azudes, aceñas, batanes y otras instalaciones que contribuyeron al desarrollo de los pueblos ribereños. El estudio que hoy traemos a estas páginas es el resultado de un actuación de arqueología preventiva realizado en el término municipal de Abánades, perteneciente a la comarca de Cifuentes (Guadalajara) y surcado por el alto 
Tajuña. Perteneció al Ducado de Medinaceli y los antecedentes de investigación arqueológica no son muy amplios, aunque es posible que se hallen algunos asentamientos de la Segunda Edad del Hierro en las cotas más altas, en la linea de otros descubiertos en términos cercanos e identificados por los proyectos de investigación realizados en la última veintena de años.

En el lugar objeto de nuestro estudio se proyecta la construcción de un complejo de turismo rural. Una vez solicitada la ampliación de calificación urbanística para la obtención de licencia de obra y actividad de nuevas edificaciones fue necesario aportar al expediente la correspondiente "Evaluación de Impacto Ambiental" con apartado sobre afecciones al Patrimonio Histórico - Arqueológico. Por ello los autores de este estudio fueron contratados para realizar un proyecto de actuación arqueológica preventiva y la obtención del permiso correspondiente en la Delegación Provincial de Educación y Cultura de Castilla - La Mancha en Guadalajara. Según nos indicaron los propietarios al inicio de nuestro proyecto, las parcelas situadas en la margen derecha del río Tajuña, se delimitaron mediante muros de mampostería de piedra. En el proceso de construcción de estas cercas y de la remodelación de otras, que pertenecían a las antiguas parcelas agrícolas y que fueron concentradas posteriormente, hace unas dos décadas, se halló en el lugar un agujero en el suelo en el que se adivinaban restos de unas paredes de piedra. Una vez agrandado este agujero, se pudo identificar la presencia de dos arcos de piedra dispuestos en paralelo. En ese momento se decidió descubrir por completo los arcos, que se inscriben en los cimientos de un edificio de planta rectangular a cuyos ángulos noreste y sudeste se adosan dos muros paralelos de unos $25 \mathrm{~m}$. de longitud hacia el este. En el ángulo sudoeste se recrece un muro adosado en ángulo de 45 grados, hacia el oeste,

1 Según definición de la RAE "hueco donde gira el rodezno de los molinos", es decir donde se incluye la maquinaria que impulsada por el agua, hace posible el giro de los dispositivos situados en el edificio principal.

2 Textualmente "en algunas casas del pueblo se han reutilizado como material constructivo estelas con epigrafía romana" (Aguado y Cuadrado, 2011: 258). El epígrafe que mencionamos se halló al realizarse una canalización en "la parte baja del pueblo". Depositada en el Museo Arqueológico de Guadalajara está realizada sobre piedra caliza (255 x 154 x que tras un desarrollo de unos 8 metros, gira para definir un paramento de planta elíptica que termina en ángulo recto a la altura del ángulo noroeste del mencionado edificio. A partir de aquí, el tramo de muro que terminaba en este último punto descrito, se halla derruido, permaneciendo los restos en el fondo del espacio que definen estos muros de mampostería. Al sur de estas estructuras y a unos $15 \mathrm{~m}$. se halla el actual cauce del río Tajuña, mientras que hacia el norte el conjunto se halla junto a una pequeña explanada que constituye el final del camino que parte de las inmediaciones del pueblo de Abánades y que atravesando la vega se adosa en su último tramo a los relieves calizos en los que se encaja el río Tajuña.

A finales del pasado mes de febrero realizamos los trabajos de campo, que consistieron en una planimetría completa de los restos de la estructura, incluyendo los "caces" de entrada y salida de aguas, que denominamos "aguas arriba" y "aguas abajo", según la terminología de la arquitectura hidráulica. Una vez realizado el levantamiento planimétrico, procedimos a la identificación de los paramentos y el estudio de detalle de cada uno de ellos, así como la estructura de planta cuadrangular - restos de un edificio de carácter hidraúlico - que conserva dos "cárcavo"1.

\section{1.- ANTECEDENTES de INVESTIGACIÓN HiS- Tórica. El término de Abánades}

El actual término de Abánades tiene una superficie de $36,3 \mathrm{~km} 2$, estando situado el núcleo bajo un cerro en la margen derecha del río Tajuña, a $1.048 \mathrm{~m}$. de altitud. Cuenta con 107 habitantes y podemos mencionar antecedentes de hallazgos de material arqueológico de cronología celtibérica y en el propio casco urbano fue hallada en 1984 un ara votiva de cronología hispanorromana $^{2}$. El único edificio notable es la

$154 \mathrm{~mm}$.) y dedicada a la divinidad celtibérica Louterde. La lectura de la misma es: LOUTERD / EAURELIA / TERTIOLA / V S L M transcrita "Lout e rd / e Aurelia / Tertiola / V(otum) S(olvit) L(ibens) M(erito)" y cuya traducción es: Para Louterde. Aurelia Tertiola en cumplimiento de su voto, de buen grado. (Fernández y Arenas, 1988). Los autores fechan el ara en la segunda mitad del siglo I a.C. apuntando la posibilidad que Louterde sea un nombre de deidad desconocido hasta el momento en esta celtiberia alcarreña. 
iglesia parroquial ${ }^{3}$. Los primeros datos históricos fiables que disponemos para estas comarcas alcarreñas se fechan a inicios de la Edad Moderna. No obstante no hemos localizado el término de Abánades en las Relaciones Topográficas de los Pueblos de España, realizadas por orden de Felipe II, en la segunda mitad del siglo XVI (Ortiz, 2002). Es muy posible que no se conservaran o que nunca fueran redactadas. Sin embargo en las respuestas del Catastro de Ensenada, realizadas entre 1750 y 1754 se dice textualmente: "A la decima séptima pregunta dijeron que en termino de este lugar hai un molino arinero propio de Isidro Díaz e Isabel Hortego vecinos de este lugar y de Francisco Romo vecino de Casanueva. Esta sito inmediato a la población sobre el arroyo que sale del Río Tajuña con su agua muele todo el año con una sola piedra." Destacamos que solo se hace mención a una estructura dedicada a la molienda. No obstante, unas décadas más tarde, tenemos el dato preciso de la existencia de un batán "en el lugar de Abánades" que nos lo ofrece la obra enciclopédica de D. Eugenio Larruga y Bonet ${ }^{4}$. El actual término pertenecía, a finales del siglo XIX, al ducado de Medinaceli, que se integraba en la provincia de Soria y como tal aparece reseñado en el tomo 22, con las escuetas citas "En el lugar de Abanades se fabrican paños, sayales, y bayetas, todo ordinario, y es tan corta cantidad, que solo se emplea un telar." (Larruga, 1792:XXII,2) y "En el lugar de Abanades hay un batan" (Larruga, 1792:XXII,150).

3 "Dominando el pueblo, en lo alto de la ladera, se alza su edificio más destacado, la Iglesia de San Pedro. Es un edificio del siglo XVI con muros de sillería y mampuesto, que sustituyó al primitivo recinto románico del siglo XIII. De aquel templo sólo se conserva la galería porticada de seis arcos, tres a cada lado del arco de medio punto de ingreso, con columnas dobles del románico tardío y capiteles esculpidos con temas vegetales y entrelazas de los siglos XIII-XIV. Su interior es de una nave con cubierta plana sobre tirantes de madera y arco triunfal de medio punto algo rebajado sobre pilares románicos que da paso a la capilla mayor de techumbre octogonal. En la capilla bautismal se abre una ventana con arquivoltas de medio punto y conserva una gran pila bautismal gallonada, posiblemente románica.

Sufrió muchos desperfectos en la Guerra Civil siendo restaurada posteriormente; una nueva intervención en 1979 se centró en la torre y los arcos de la galería". (Aguado y Cuadrado, 2011: 258).
Ya a inicio del siglo XIX, contamos con los datos del Diccionario de Sebastíán Miñano ${ }^{5}$ que no nos aporta nada a nuestro propósito, no citando ningún ingenio en el lugar. No obstante la fuente mas precisa de este siglo XIX es la del Diccionario de Madoz (1847), donde reza que el término pertenece a la diócesis de Sigüenza y partido judicial de Cifuentes, con 27 vecinos o 125 almas. El casco de 28 casas "de mala construcción de un solo piso, que componen malas calles, irregulares y sin empedrar: el ayunt. tienen casa propia y en ella la cárcel; hay también pósito, cuyo fondo consiste en una fan. de trigo y 7 medias de avena. La igl. parr. nada ofrece de notable; tiene la advocación d la Cátedra de San Pedro. (...) riégale el r. Tajuña, que marca de N. á O., sobre el cual hay un puente de sillería con 3 ojos y 9 varas de elevación, un molino harinero y un batán; cría buena pesca de truchas, anguilas, barbos y cangrejos y no pierde su corriente" (Madoz, 1847:36). Vuelve a aparecer la mención al molino harinero y al batán que también debe ser accionado por la corriente del río Tajuña. El silencio del término en otras fuentes del siglo $\mathrm{XX}$ es prácticamente total, excepto la reconstrucción de la iglesia tras la última guerra civil (19361939), cuyos efectos aún son apreciables en al oeste del casco urbano, cual es una línea de trincheras. No aparece en los inventarios de arquitectura popular de Luis Feduchi (1984) ni en los repertorios de arquitectura fortificada (Jiménez, 1992) arquitectura desaparecida (García de Paz, 2003) o monumentos (García López, 2001). También se halla ausente del estudio de Pavón Maldonado (1984) sobre los antecedentes hispanomusulmanes de Guadalajara.

También se recoge descripción y planimetrías del monumento en Ruiz Montejo et al. (1992).

4 Véase al respecto la síntesis sobre esta importante obra de la historia económica de algunos de los reinos españoles de finales del siglo XIX (Durán, 1997).

5 "ABANADES, L. S. de Esp., prov. de Guadalajara, part. y obisp. de Sigüenza, ducado de Medinaceli. A.P. , 36 vecinos, 147 hab., 1 parr. Sit. en terr. pedreg. á or. del Tajuña. Prod.: trigo, ceb., avena y algunas legumb., cáñamo y patat., buenos montes de encina y roble, pastos en que se mantiene bastante gan. vac., lan., cabr. y algunas colm. Conf. con los pueblos de Renales, Cortes, Laranueva, Sacecorbo y Canredondo, todos de iguales ó semejantess prod. Hay en esste pueblo una campana que tiene mas de 1,024 años de antig. Dist. 11 leg. O. de la cap., 5 N. O. de Sigüenza, 9 E. de Molina y 3 S. de Cifuentes. Contr. con Medinaceli. (Miñano, 1826, vol. 1: 3)". 


\section{2.- Arqueología de la Arouitectura y ELEMENTOS EDILICIOS CONSERVADOS}

La arqueología de la arquitectura supone tres estrategias de trabajo principales, cuales son la Estratigráfica, la Tipológica y la auxiliar de otras ciencias y técnicas. En este sentido "La lectura estratigráfica completa, además, la secuencia temporal con otras intervenciones de menor importancia y llama la atención sobre elementos que suelen pasar desapercibidos o indican cambios en los usos originales. Una segunda consecuencia del análisis estratigráfico es que confirma cual era la planta y estructura original de edificio.” Además “...como sabemos, la secuencia estratigráfica posee un tercer interés cuando se consigue relacionar con secuencias formales de carácter tipológico o con datos cronológicos de carácter absoluto" (Caballero Zoreda, 2001:222). El proceso debe ser amplio y no solo observar los detalles ya que "...hay que tener en cuenta que el edificio es un objeto muy complejo, poco parangonable, por ejemplo, con una cerámica. Cada uno de sus caracteres pudo deberse a la influencia o grupos de trabajo muy distintos. Referirnos solo a uno de ellos (el aparejo) equivoca nuestra comprensión de los procesos de trabajo (aparejo; técnicas decorativas), formales (elementos singulares), estilísiticos (decoración), estructurales (arcos, bóvedas o armaduras) y proyectarles)".

En otros estudios se establecen una serie de líneas de trabajo que asumimos y hemos aplicado en la actuación arqueológica que ha sido el origen de estas líneas (Tabales, 2001). De esta forma el sistema descansa en tres preceptos, cuales son una estrategia global de intervención ${ }^{6}$, un método de intervención y registro de datos en el que se suele aplicar el método "Harris" con puntualizaciones, además de aplicar criterios de representación gráfica y modelo de fichas de control y de registro, consistentes en Unidades, Muestreos, Control tipológico y Control de obras y por último en la formación de equipos de trabajo multidisciplinares, que puedan asumir el estudio global del edificio. En resumen este autor nos expone los fines últimos del proceso... "Por otro lado, el conjunto

6 "una propuesta de auscultación inicial del inmueble mediante las oportunas comprobaciones estructurales y tipológicas que desembocan en la elaboración de las primeras hipótesis; ésta estrategia descansa además sobre un desarrollo metódico en el que los análisis de paramentos (estudios estratigráficos - análisis tipológicos - estructurales ) tienen una rele- descansa sobre unas premisas conceptuales que impregnan todo el discurso; entre estos principios destacan la vinculación esencial entre el análisis histórico arqueológico y la rehabilitación, el estudio generalizado (no parcial) del inmueble, la compresión diacrónica, la inserción geohistórica y tipológica en el entorno, el análisis selectivo primando lo general sobre lo anecdótico, la capacidad consultiva reglada en las tareas de rehabilitación, etc..." (Tabales, 2002:11).

Este método de Arqueología de la Arquitectura se ha aplicado desde hace una veintena de años. $\mathrm{Al}$ respecto podemos destacar, entre otros muchos trabajos, los desarrollados en la provincia de Sevilla, tanto en la capital - Catedral y Giralda, Palacio de los Marqueses de Marchelina, Hospital de las Cinco Llagas, Alcázar, Cartuja, Palacio Altamira, Palacio de los Mañara, Cuartel del Carmen y Monasterio de San Clemente - como en la provincia - Iglesia de Santa Ana de Guadalcanal y Puerta de Córdoba de Carmona (Tabales, 2001, 2001b, 2001c, 2001d; Tabales et alii, 2001; Tabales y Romero, 2001; Tabales y Romero, 2001b; Tabales, Pozo y Oliva, 1999). También en la catedral de Santa María de Vitoria se han desarrollado trabajos de este tipo (Azcárate, 2001), no supeditándose solo este método para grandes estructuras arquitectónicas, sino también para otras de menor tamaño, como iglesias rurales del norte peninsular (Caballero, 2001). En esta misma línea de estudios existen otros, menos desarrollados aún pero que creemos que tienen un enorme futuro.

Nuestra primera impresión de los restos del edificio es la existencia de dos cárcavos por los que discurría el agua en sentido este - oeste, insertos en un edificio con paramentos muy alterados y del que no se conserva el cuerpo en el que se albergaba la maquinaria hidráulica. Se conservaría pues parte del "cuerpo de aguas" en terminología molinológica, reconstruyéndose hace unas dos décadas los caces de entrada y salida del agua. $\mathrm{Al}$ respecto se halla una inscripción en el paramento sur que reza "Arcos del molino viejo", fechada en 1989 y que sitúa el momento en que se

vancia jerárquica. Además supone una división en actuaciones en el subsuelo - en el interior de los edificios y por las necesidades de la investigación - , mediante sondeos estratigráficos, cortes prospectivos, cortes extensivos y controles de obra" (Tabales, 2001). 
terminó la reedificación de los paramentos tras el descubrimiento de los dos cárcavos. Estos caces se adosaron a los restos originales del primitivo edificio. Pudimos apreciar que en su momento debieron de existir caz de entrada y salida del cuerpo de aguas del edificio. Solamente podemos definir como original parte del resto del paramento sur aguas abajo, que mantiene un ángulo distinto de $90^{\circ}$ con respecto al edificio. Anotamos que no hemos hallado ningún resto estructural que nos haga pensar en caces de caudal comprimido o de "cubos", como ocurre en otros lugares de España donde el caudal de los ríos no es ni alto ni permanente. Es muy posible que el caz primitivo de entrada se alineara con los cárcavos y que se imbricaran con los sillares que son el inicio de estos cárcavos. No tiene sentido ofrecer resistencia a las aguas presentando parte de los paramentos perpendiculares a los mismos.

No ha sido sencillo determinar los morteros originales, que evidentemente aparecen en los sillares de los cárcavos. Están compuestos de mezcla de cal y arena, y son muy similares al empleado en parte de las reconstrucciones realizadas en el edificio y los paramentos adosados. Hemos de señalar que el paramento norte del caz aguas abajo se halla desplomado al interior del mismo. Es posible que el hueco que existe en el ángulo superior noroeste del paramento oeste del edificio fuera parte de la estructura general, ya que seguramente el caz de salida llegara hasta este punto. Creemos que los caces de salida debían de ser siempre más anchos que los de entrada. La parte superior del edificio se halla también reconstruido, presentando unos pretiles donde aparece mortero de cemento, hallándose la superficie cubierta de hierba, aunque no se aprecia resto alguno de la maquinaría que en su día debió de albergarse en el interior del edificio. También se aprecia como el camino que viene desde el pueblo de Abánades termina en este lugar, ya que el relieve de la hoz en la que entra el Tajuña en este lugar se cierra aguas abajo de la estructura que nos ocupa en este estudio.

El conjunto que se conserva constituye los restos de un edificio de planta cuadrangular de unos seis metros de lado, con unos pretiles hacia oeste, sur y oeste de unos $75 \mathrm{~cm}$. de altura y casi cuatro metros bajo la cota 0 , que se correspondería con la pequeña explanada descrita. Este edificio aparece atravesado por dos bóvedas de cañón des- arrolladas a partir de arcos de medio punto algo rebajados, que tienen una luz de aproximadamente dos metros y longitud de seis metros, atravesando el edificio en sentido este - oeste. El conducto situado al sur presenta su entrada oeste tapiada por ladrillos de hueco simple trabados por mortero de cal y cemento. La fábrica de estos conductos es de sillares bastante regulares, aparejados a la misma altura, aunque no todos de la misma longitud. La cota de estos conductos se halla en el fondo de los dos espacios que quedan definidos a este y oeste del edificio, de planta rectangular al este y de planta elipsoide al oeste. y que serían la reconstrucción de los caces de entrada y de salida del ingenio hidráulico. Es de hacer notar que en el entorno del conjunto que describimos se halla una cerca que separa las parcelas más cercanas al río, al este con el camino descrito y al oeste con el inicio de la cuesta de los relieves calizos también mencionado. El conjunto se halla muy limpio, invadido solamente por maleza en el fondo de los dos ámbitos adosados y restos de algunas hogueras producto de la poda de los álamos que pueblan el entorno. No olvidemos tampoco los restos de uno de los muros desprendidos quizás no hace muchos años.

La cercanía al cauce del río y ciertas hendiduras y "hornacinas" realizadas en los paramentos de sillares, además de la propia disposición de los dos conductos nos induce a plantear la hipótesis de la adscripción de los restos del edificio a usos hidráulicos, evidentemente extinguidos en la actualidad. La literatura consultada para la redacción de proyecto de actuación arqueológica nos indicaba la presencia de un molino en el término municipal hacia la mitad del siglo XVIII y de un molino y de un batán al menos entre finales de esta centuria y la mitad de la siguiente. Un autor contemporáneo adscribe el edificio del molino a una actual vivienda situada junto al puente que se halla a la entrada del pueblo, en la carretera que une este con Renales y que conserva una acequia de alimentación del ingenio hidráulico. Este mismo autor cita la existencia del batán a unos 2 $\mathrm{km}$. del pueblo aguas abajo del mismo, ya que los productos que se utilizaban en los batanes tendían a contaminar el agua (Medina, 2000-2001).

No hemos detectado ningún material arqueológico en superficie, ni siquiera los usuales fragmentos cerámicos de cronología contemporánea. Tampoco podemos aportar datos sobre estratigra- 
fía de sedimentos pues no se han realizado catas estratigráficas. Respecto a la estratigrafía muraria, podemos apreciar la presencia de al menos dos momentos básicos en el conjunto que nos ocupa, cual es el momento de construcción del edificio y del que queda parte del cuerpo de aguas y de la posterior reconstrucción de parte del edificio y los caces. Por ello, tampoco disponemos de elementos arqueológicos de naturaleza no inmueble para fechar con seguridad la estructura. La fábrica edilicia original si tiene todo el aspecto de haber sido realizada en el siglo XVIII, pero sería necesaria una excavación arqueológica "en toda regla" para describir la conexión del cuerpo de aguas conservado con la parte superior del posible batán y así identificar con todo detalle el lugar donde se instalaría la maquinaria del ingenio hidráulico.

\section{3.- DisCUSIÓN. IDENTIFICACIÓN Y CRONO- LOGÍA DE LA ESTRUCTURA}

El control y aprovechamiento del agua es consustancial a la especie humana. No hemos de remontarnos a la Prehistoria, pero si a la Edad Media, donde la utilización de los recursos hídricos vertebra los paisajes del interior peninsular. Este dominio del agua será fundamental para el afianzamiento de las élites bajomedievales (Segura, 2003), quedando bien expresado en el valle madrileño del río Tajuña, concretamente en las actuales localidades de Tielmes y Perales de Tajuña (Martín Viso, 2003). La literatura sobre molinología es muy extensa ${ }^{7}$. Desde los gruesos tratados de las estructuras de la cornisa cantábrica (Aguirre, 1998), hasta incluso bibliografías (Elías, 1989b), congresos y reuniones sobre el tema (Elías, 1989a; Glik et al., 2000). No obstante el punto de partida no es muy lejano, los trabajos clásicos de Caro Baroja $(1983 ; 1995)$ u otros más recientes (González Tascón, 1992). Abundantes también son los glosarios, desde época medieval (Argemí et al., 1995, García Manso, 1999) o moderna (Rodríguez Monteoliva, 1989).

7 Al respecto hemos de hacer un inciso y es que cuando hemos comprobado el carácter hidráulico de la estructura de Abánades, hemos abundado en la copiosa literatura molinológica, comprobando la parquedad de estudios que presentan
No obstante hemos podido comprobar que la mayoría de los textos constituyen la nómina y las someras descripciones de conjuntos de estructuras hidráulicas situadas en una cuenca fluvial, aunque en algunos estudios se abunde en las características edilicias de las estructuras (Sorroche, 1999). Escasas son las intervenciones arqueológicas sobre estructuras industriales hidráulicas y ejemplo de ellas serían las realizadas en el denominado "Molí de Codina" en la población ilerdense de Tárrega (Badías y Saula, 1999), o el Molino de la Alegría de Córdoba (Córdoba, 2001). De la literatura que hemos consultado para este proyecto son bastante interesantes los trabajos realizados en Almería (Cara et al., 1996; 1999) en Cartagena (Berrocal, 2008) Córdoba (Córdoba et al., 2008) o en el Aljarafe Sevilano (Valor, 1989). Por no perdernos en el bosque de esta literatura, mencionaremos los lugares más cercanos al que nos ocupa, como la cuenca del río Tajo (Miguel y Segura, 1998) en Colmenar de Oreja (Baltanás, 1998), o el curso del río Manzanares en Colmenar Viejo (Santamaría y Rohmer, 1989; Colmenarejo y Colmenarejo, 1991), la cuenca baja del río Tajuña (García Grinda, 1990) o la Sierra Norte (Bartolomé et al., 1995). La molinería alcarreña apenas cuenta con un par de referencias (Medina, 2000-2001; Castellote, 2008) y en otras cuencas hidrográficas de la meseta sur citamos los molinos de la provincia de Cuenca (García Cuevas, 2005) y los de Toledo (Méndez, 1998). Ya habíamos comentando en el proyecto el dato de la presencia en Abánades de un molino y un batán. Al respecto Leopoldo Medina del Cerro (2000-2001) identifica las dos estructuras en el entorno del pueblo: Al respecto Eulalia Castellote (2008) apenas si menciona la cita del Catastro de la Ensenada, sin ninguna noticia más. Por ello sugerimos que el resto de edificio hidráulico se corresponda con un batán, máxime cuando hemos visto un caz o acequia muy bien conservado en las inmediaciones de un edificio, en el mismo núcleo urbano y también en la margen derecha del Tajuña, pero aguas arriba de nuestra estructura. ${ }^{8}$.

planimetrías y de los trazos poco fiables de la mayoría de los planos publicados.

8 Los batanes se solían instalar aguas a bajo de los pueblos. 
Identificar un batán a partir de los cárcavos es imposible pues lo único que se diferenciaba de los molinos harineros era en la maquinaria albergada en el cuerpo superior del edificio. Hemos indagado en la literatura que citamos en las siguientes páginas con desigual resultado. El batán que se halla anexo al Molino de la Alegría de la ciudad de Córdoba tiene una planta muy parecida a la estructura que nos ocupa en este estudio ( 7 x $4 \mathrm{~m}$.) y consta de una estancia abovedada de una sola planta, además del "cuerpo de aguas", aunque en el estudio original no se cita con estos términos. Presenta tres fases documentadas arqueológicamente y datadas en los siglos XX, XVI y XV. En la última fase debió de ser adaptada para la molturación de cereal, con la presencia de los restos de una tolva y un molino eléctrico. Los restos del batán se datan por la fábrica de sillarejo de los alzados de los paramentos del pequeño edificio, además de los restos cerámicos que se hallaba en los sedimentos que sellaban estas estructuras. Se fechan en la segunda mitad del siglo XVI. Aún por debajo de este nivel aparecen los restos de una sala de producción (quizás para la molturación de cereal o bataneo de lana) que se datan en el siglo $\mathrm{XV}$. Los autores creen que el batán estuvo en funcionamiento hasta el siglo XVIII, o posiblemente el siglo XIX. Seguramente en la primera mitad del siglo XX debió de adaptarse a la molturación de cereal. (Córdoba, 2001). Del mismo autor es un texto meridiano sobre el ser y el funcionamiento de los batanes (Córdoba 2011), que en un trabajo anterior nos muestra ejemplos de documentación notarial para conocer las partes y la maquinaria de un molino (Córdoba, 2003), en la línea de otros trabajos similares (Sánchez Ferrer, 1990). Precisamente en este último estudio se relaciona los batanes de las lagunas de Ruidera, hoy en el término albacetense de Ossa de Montiel con la Real Fábrica de Paños de Guadalajara

9 "En el siglo XVIII se instalaron cuatro batanes de paños: uno en Herrera de Pisuerga, (esclusa $7^{\mathrm{a}}$ ) dos en Frómista, (esclusas $17,18,19$ y 20) y otro en Calahorra de Ribas. (Esclusas 22,23 y 24). En los grupos de esclusas los batanes se emplazaron siempre aguas abajo de los molinos para no perjudicarles con sus aguas contaminadas. (Recordemos que en los batanes se utilizaban productos, como las cenizas, cortezas y cal, para lavar y enfurtir los paños y a veces tintes para colorearlos).

Todos los batanes respondían inicialmente al mismo patrón constructivo. Empleaban, siguiendo la tradición medieval, la rueda hidráulica para accionar, sin reducir la velocidad, el eje horizontal en el que van situadas las levas que accionan
(González Enciso, 1980; 1988; 1994; 1996; 2001), que tuvo su esplendor entre 1767 y 1797, citando como las fábricas de paños extendían su influencia en las áreas con cursos de agua, ya que en los lugares de origen de las manufacturas los batanes eran ciertamente escasos. Así, en 1779 funcionaba un batán de cuatro pilas en San Fernando de Henares y otro de doce en Guadalajara. En las mencionadas lagunas los batanes apenas presentan estructuras, sino las propias del caz, cubo, etc..y el ingenio del batán, prácticamente sin edificios en origen, con la salvedad de la necesidad del denominado "prado de los lienzos", para poder secar las manufacturas. En nuestro caso, el batán de Abánades, pudiera haber estado relacionado con la Real Fábrica de Paños de Brihuega, situada aguas abajo en el propio río Tajuña (Domínguez, 1982; Martín Galán, 1983).

En la estructura que analizamos destaca sobremanera la fábrica isodómica de sillares, con bóveda de cañón desarrollada a partir de un arco de medio punto algo rebajado. Creemos que muy bien podría tener su origen a finales del siglo XVIII, teniendo en cuenta que la última mención es la del Diccionario de Madoz (1847). Un paralelo que podemos mencionar de batanes es el complejo que se hallaba a las orillas del Canal de Castilla, ingenio hidráulico Ilustrado que recorre las provincias de Palencia y Valladolid. Citamos literalmente pues nos ilustra sobre el funcionamiento de aquellos batanes textiles (Geijo, 2005) . En este estudio únicamente se explican los artefactos construidos entre 1759-1804, la construcción del Ramal Norte (1759-1791) y parte del Ramal Sur (1792-1804) entre Alar del Rey (Esclusa 01) y Soto Albúrez (Esclusas 34-35-36). Al frente de las obras estuvieron Fernando de Ulloa y Juan de Homar, bajo iniciativa estatal.

los mazos. Cada batán tenía instaladas dos ruedas en el centro del edificio que movían sus correspondientes juegos de mazos a cada lado. Los edificios fueron pensados inicialmente para alojar tres pilas a cada lado de cada rueda y sobre cada pila batían dos mazos alternativamente.

La altura del cuerpo de aguas (entre 5 y 6 metros) es mayor que en los molinos y el diseño de las canales permite la instalación de las ruedas, dejando un aliviadero central. Las dimensiones de la planta, (unos 17 metros de largo por 9 de ancho) son algo diferentes a las de los molinos al adaptarse ahora a la instalación de las ruedas de cierre, las pilas y los correspondientes juegos de mazos. (Gupijo y Zulueta 2005) 
Volvemos al entorno de las cuencas del Alto Tajo. En Colmenar Viejo podemos citar un documento fundamental para la arquitectura y descripción del término en el siglo XX, (Berlinches y Moleón 1991: 178-190), con la descripción de los molinos de Peña Laguna, de los Cuatro Ojos, de Arriba del Grajal, de en Medio del Grajal y de Abajo del Grajal, respectivamente (ibid. 204207). También destaca el Puente del Grajal (Ibid.: 236) y puente del Batán (Ibid.: 237), como estructuras relacionadas con las vías de comunicación que unían casco urbano y molinos. El Molino de Arriba del Grajal presenta una estructura de dos cárcavos contíguos parecido al de Abánades.

Los batanes eran ingenios que movidos por la corriente de ríos o acequias que atravesaban conductos llamados cárcavos situados bajo pequeños edificios y que tenían dos pisos principales. En el inferior, situado a la misma cota que las corrientes de agua y dentro de los cárcavos se alojaban ruedas (denominadas rodeznos) que montadas sobre ejes de madera (generalmente troncos arbóreos denominados árbol) con una serie de mecanismos para detener el movimiento o incluso compuertas para impedir el paso del agua. En el piso superior se hallaba un entramado de madera en forma de cubo (castillo) que albergaba generalmente dos martillos que se movían mediante un mecanismo denominado árbol de levas. Estos martillos golpeaban en un recipiente también de madera en el que colocaban tejidos de lana impregnados de distintas materias y que mediante el machacado se pretendía dotar a los tejidos de una mayor resistencia en su urdimbre y hacerlos así adecuados para transformarlos en prendas de vestir. El conjunto que describimos consiste en dos cárcavos originales de sillería bastante bien conservados, con restos también originales del primitivo edificio del batán, que posteriormente fue recrecido por alzados de mampostería, formando el conjunto que hoy podemos apreciar de los restos de un batán posiblemente edificado a partir de la segunda mitad del siglo XVIII, quizás transformado en molino harinero a partir del final del siglo XIX - con la decadencia de las manufacturas que se realizaban en los batanes - y posiblemente abandonado a mitad del siglo XX, con el definitivo monopolio de las fábricas harineras peninsulares.

\section{4.- Conclusiones. Una estructura INÉDITA EN EL ALTO TAJUÑa.}

La estructura objeto de nuestro análisis conserva dos cárcavos de fábrica de sillares y planta de bóveda de cañón desarrollada a partir de un arco de medio punto algo rebajado. En los sillares aparecen algunos huecos que se corresponderían con los dispositivos de control de la rueda (rodezno) y que eran activados desde la planta superior. Dichos cárcavos se hallan dispuestos en paralelo en la parte inferior o "cuerpo de aguas" de un edificio de planta cuadrangular. A partir de los extremos del paramento este del edificio se desarrollan dos muros tangentes y paralelos de unos veinte metros de longitud, que llegan a alcanzar los cuatro metros de profundidad a partir de la cota actual del terreno. A partir del paramento oeste se desarrolla un muro tangente en un ángulo de unos $45^{\circ}$, que a los ocho metros gira definiendo planta elíptica para volver hacia el ángulo noroeste del edificio. Este tramo del muro se halla derruido, permaneciendo sus restos en el fondo del espacio definido por los muros. La fábrica de los cárcavos nos remite a una cronología del siglo XVIII y por indicios arqueológicos y documentales podríamos fecharlo a partir de la segunda mitad de dicho siglo. La fecha del final de la estructura es difícil de precisar, pues en sus últimas fases de funcionamiento pudo ser convertido en molino harinero. Como conclusión a este apartado hemos de mencionar, que si bien no dudamos de la adscripción de los restos de la estructura que nos ocupa a un edificio destinado a aprovechar la fuerza del cauce del río Tajuña para mover una maquinaria destinada a la molturación de grano o a proporcionar la energía suficiente para mover otros elementos mecánicos, cuales son los martillos de un batán, no podemos adscribir con seguridad los restos de la estructura a uno u otro uso. Mientras no contemos con más elementos de diagnóstico que los actuales no podemos decantarnos, aunque pensamos que en su origen pudo ser un edificio destinado a batán, edificado a partir del siglo XVIII y que seguramente fue transformado en molino de grano, a partir de la segunda mitad del siglo XIX.

En el lugar se prevé la construcción de un mirador sobre la planta cuadrangular con áreas de balneario en los espacios definidos por los muros situados a este y oeste de los restos del edificio 


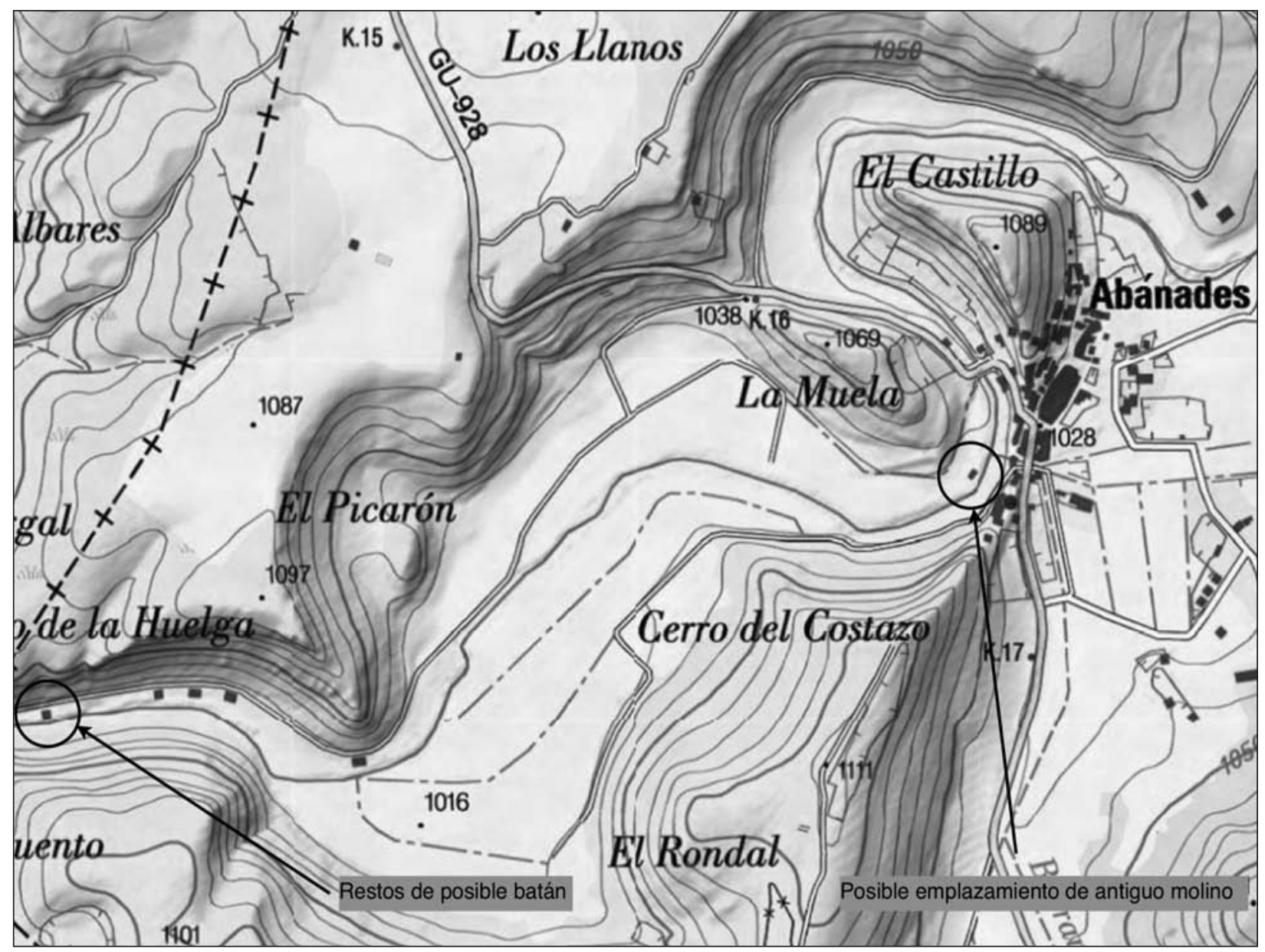

Figura 1. Plano de situación batán de Abánades

del batán. En principio los cárcavos quedarían integrados en la nueva construcción como exponente de la actividad extinta del edificio. No obstante el conjunto debe permanecer alejado del contacto con el agua, que aunque fue concebido para ello, hoy no tendría sentido mantener el sistema inundado, sobre todo por no poder garantizar la corriente de agua (a no ser que se desviara el río y se activara de nuevo la canalización por la que se conducía el agua hacia los cárcavos.

La integración de los restos del Batán Moderno de Abánades si duda contribuirá a incrementar el valor del Patrimonio Histórico del término y supondrá un buen ejemplo de compromiso social por parte de los promotores del proyecto. Este tipo de actuaciones dota de valor añadido al conjunto que se pretende construir, además de contribuir a la salvaguarda de un elemento perteneciente a nuestro patrimonio histórico, que aunque muy extendidos por toda la geografía peninsular, no se hallan bien documentados y difundidos tanto en su conjunto como en el detalle de los ingenios mecánicos movidos mediante energía hidráulica que poblaban las orillas de los ríos españoles hasta mediados del pasado siglo.

\section{5.- Agradecimientos}

A Dña. Flora Antón Ochoa y D. David García Marcos, promotores del proyecto agradecemos el interés y las facilidades que nos han brindado para la realización del presente estudio, además de la financiación del mismo en su proyecto de arqueología preventiva. D. Jesús Díaz Dávila, arquitecto director facultativo del proyecto de construcción, nos comunicó verbal y gráficamente lo proyectado para la estructura objeto de nuestro análisis. D. Luis Olías Barrero, director del proyecto de Evaluación Ambiental desde el primer momento nos brindó su estudio e hizo posible la inserción de nuestro trabajo de patrimonio histórico en el documento ambiental final. De igual forma hemos de agradecer a Dña. Teresa Sagardoy Fidalgo arqueóloga de la Delegación Provincial 
de Cultura de Castilla - la Mancha en Guadalajara, las directrices y coordinación de la actuación que ha originado el presente texto. D. Pedro José Pradillo Esteban nos orientó con sus siempre acertados comentarios como conocedor exhaustivo de la literatura histórico-arqueológica alcarreña. Finalmente, Belén Gallego Vara tradujo, con un rigor impropio de su temprana edad, el resumen que encabeza estas líneas.

\section{6.- REFERENCIAS BIBLIOGRÁFICAS}

AGUADO DÍAZ, F. y CUADRADO PRIETO, M.A 2011: "Guadalajara". En Palomero Plaza, S. y Vázquez González, A.: Castilla - La Mancha. Guía de Patrimonio Cultural. Toledo: Consejería de Educación, Ciencia y Cultura. vol. 3. voz Abádenes. 258 p.

AGUIRRE SORONDO, A. 1998: Tratado de molinología: (los molinos de Guipúzcoa). San Sebastián. $841 \mathrm{p}$.

ARGEMÍ, M.; BARCELÓ, M.; CRESSIER, P.; KIRCHNER, H. y NAVARRO, C. 1995: "Glosario de términos hidráulicos". En El agua en la agricultura de al-Andalus. Barcelona, El Legado Andalusí: 163-189.

AZKARATE GARAIOLAUN, A. 2001: “Análisis de la evolución histórico - constructiva de la catedral de Santa María de Vitoria - Gasteiz (Aplicación de la "Arqueología de la Arquitectura" en un modelo complejo)". Actas del V Congreso Arqueología Medieval Española, vol. I: 177 - 212.

BADÍAS MATA, J. y SAULA I BRIANSÓ, O. 1999: "La interveció arqueológica al jaciment del Molí de Codina de Tárrega (Lleida)". En Actas de las II Jornadas de Molinología (Tarrasa-La Pobla de Cérvoles, 30 de septiembre a 3 de octubre de 1998). Lérida: 36-47.

BALTANÁS, H. 1998: "Los molinos de la presa de la Aldehuela (Colmenar de Oreja): Obras de remodelación de un complejo hidráulico en el río Tajo (siglos XVI y XVII)". Actas del II Congreso Nacional de Historia de la Construcción (La Coruña, 22-24 de octubre de 1998), La Coruña: 35-40.

BARTOLOMÉ MARCOS, L.; BERZAL SIGUERO, A. y MÉNDEZ SÁNCHEZ, J. 1989: "Máquinas de agua de la sierra norte de Madrid: pasado, presente y futuro posibles". En Elías Pastor. L.V. (coord.) Los molinos: cultura y tecnología: 43-78.

BERLINCHES ACÍN, A. y MOLEÓN GAVILANES, P. 1991: Arquitectura y desarrollo urbano. Comunidad de Madrid. Zona Centro I. Madrid.
Dirección General de Arquitectura de la Comunidad de Madrid. Voz "Colmenar Viejo": $175-240$.

BERROCAL CAPARRÓS, M.C. 2008: "Estudio de estructuras emergentes y documentación arqueológica de tres molinos del área del Monasterio de San Ginés de la Jara". Actas de las XIX Jornadas de Patrimonio Cultural de la Región de Murcia. (Cartagena, Alhama de Murcia, La Unión y Murcia, 7 de octubre al 4 de noviembre 2008) Vol. 1: 209-212.

CABALLERO ZOREDA, L. 2001: “Aportación a la arquitectura medieval española. Definición de un grupo de iglesias castellanas, riojanas y vascas". Actas del V Congreso de Arqueología Medieval Española, vol. I: 221 - 233.

CARA BARRIONUEVO, L. et al. 1996: Molinos hidráulicos tradicionales de los Vélez (Almería). Etnografía y Cultura Popular, Cuadernos monográficos ; 32. $122 \mathrm{p}$.

CARA BARRIONUEVO, L. et al. 1999: Los molinos hidráulicos tradicionales de la Apujarra (Almería) Almería : Instituto de Estudios Almerienses. 196 p.

CARO BAROJA, J. 1983: Tecnología Popular Española, Madrid, Editora Nacional, 597 p.

CARO BAROJA, J. 1995: Historia de los molinos de viento, ruedas hidráulicas y norias. Madrid : Instituto para la Diversificación y Ahorro de la Energía.

CASTELLOTE HERRERO, E. 2008: Molinos harineros de Guadalajara. Toledo, Consejería de Cultura, Turismo y Artesanía de Castilla-La Mancha. Serie Patrimonio Histórico - Artístico, 22, $578 \mathrm{p}$.

COLMENAREJO GARCÍA, F. y COLMENAREJO ROMERA, P.L. 1991: Molinos y batanes de Colmenar Viejo. Colmenar Viejo : Ayuntamiento, Delegación de Cultura, 262 p.

CÓRDOBA DE LA LLAVE, R. 2001: "Intervención arqueológica de apoyo a la restauración en un edi?cio industrial: el molino de la Alegría (Córdoba)". Actas del V Congreso de Arqueología Medieval Española, Valladolid, Junta de Castilla y León, vol. I: 361-369.

CÓRDOBA DE LA LLAVE, R. 2003: "Los molinos hidráulicos de la cuenca del Guadalquivir a fines de la Edad Media: instrumental y equipamiento técnico". Anuario de Estudios Medievales 33/1: 291-337

CÓRDOBA DE LA LLAVE, R. 2011: "Los batanes hidráulicos de la cuenca del Guadalquivir a fines 
de la Edad Media. Explotación y equipamiento técnico". Anuario de Estudios Medievales 41, 2: 593-622.

CÓRDOBA, R.; CUENCA MONTILLA, J.; HERNÁNDEZ ÍÑIGO, P. y ORTIZ GARCÍA, J. 2008: Los molinos hidráulicos del Guadalquivir en la ciudad de Córdoba. Estudio histórico y arquitectónico, Madrid, CEHOPU, 101 p.

DURAN PUJOL, M. 1997: "Las memorias políticas y económicas de Eugenio Larruga: una reedición necesaria”. Revista de Historia Industrial, 11. 221-230.

ELÍAS PASTOR, L.V. (coord.) 1989a: Los molinos: cultura y tecnología. (Sorzano, La Rioja). Centro de Investigación y Animación Etnográfica, Madrid: Instituto de Conservación y Restauración de Bienes Culturales, 335 p.

ELÍAS PASTOR, L.V. 1989b: "Bibliografía sobre tema molinar", en L-V. Elías Pastor (coord.) Los molinos: cultura y tecnología. (Sorzano, La Rioja): Centro de Investigación y Animación Etnográfica [Madrid] : Instituto de Conservación y Restauración de Bienes Culturales: 121-144.

DOMÍNGUEZ SANTAMARÍA, A.R. 1982: "La Real Fábrica de Paños de Brihuega". Wad-al-Hayara 9: 163-178.

FEDUCHI, L. 1984: Itinerarios de Arquitectura popular española. 5.- La Mancha, del Guadiana al mar. Barcelona. editorial Blume, 518 p.

FERNÁNDEZ GALIANO, D. y ARENAS ESTEBAN, J.A. 1988: "Una nueva divinidad celtibérica documentada en Abánades (Guadalajara)". Wad-al-Hayara 15: 371-376.

GARCÍA CUEVAS, A. 2005: Los molinos hidráulicos harineros en la provincia de Cuenca, Cuenca, Diputación Provincial, 609 p.

GARCÍA GRINDA, J.L. 1990: Recuperación de los Molinos del Tajuña, Madrid, Comunidad de Madrid. $2^{\mathrm{a}}$ ed., $202 \mathrm{p}$.

GARCÍA LÓPEZ, J.C. 2001: Catálogo Monumental de Guadalajara. Edición de 2001. Guadalajara, Aache Ediciones, 1 CD Rom.

GARCÍA MANSO, E. 1999: "La terminología medieval respecto a la tipología, función y tamaño de las instalaciones molineras". En Actas de las II Jornadas de Molinología, Lleida, Institut d'Estudis Ilerdens: 66 - 76.

GARCÍA DE PAZ, J.L. 2003: Patrimonio Desaparecido de Guadalajara. Guadalajara: Aache, col. Tierra de Guadalajara n ${ }^{\circ}$ 46, 246 p.

GEIJO BARRIENTOS, J.M. y ZULUETA PÉREZ, P. 2005:"’De artefacto a fábrica: Recuperación gráfica de la arquitectura industrial del siglo XVIII en el Canal de Castilla". En Actas del XVII Congreso Internacional Ingefraf - ADM, Sevilla http://www.ingegraf.es/pdf/titulos/COMUNICACIONES\%20ACEPTADAS/M14.pdf.

GLIK, T.F., GUINOT, E. y MARTÍNEZ, L.P. (Eds.) 2000: Els molins hidràulics valencians. Tecnologia, història i context social. Institució Alfons el Magnànim. Diputació de València. Valencia, 503 p.

GONZÁLEZ ENCISO, A. 1980: Estado e industria en el S.XVIII: La fábrica de Guadalajara, Madrid, Fundación Universitaria Española.

GONZÁLEZ ENCISO, A: 1988: "La industria de la lana en el siglo XVIII". En La economía de la Ilustración / coord. por Carmen María Cremades Griñán, 69-98.

GONZÁLEZ ENCISO, A. 1994: “Inversión pública e industria textil en el siglo XVIII. La Real Fábrica de Guadalajara". En Notas para su estudio. Lecturas de historia empresarial / coord. por José Luis García Ruiz, Juan Hernández Andreu: 75-99.

GONZÁLEZ ENCISO, A. 1996: “Guadalajara y su Real Fábrica en el siglo XVIII". Wad-al-Hayara 23, 23-30.

GONZÁLEZ ENCISO, A. (coord.) 2001: El negocio de la lana en España (1650-1830). Universidad de Navarra, Ediciones Universidad de Navarra. EUNSA.

GONZÁLEZ TASCÓN, I. 1992: Fábricas hidráulicas españolas. Ministerio de Obras Públicas y Transportes. CEHOPU. $1^{\text {a }}$ Ed. de 1986, 531 p.

JIMÉNEZ ESTEBAN, J. 1992: Castillos de Guadalajara. Madrid: Libros Penthalon. 2 vols.

LARRUGA Y BONETA, E. 1792: Memorias políticas y económicas sobre los frutos, comercio, fábricas y minas de España: con inclusión de los reales decretos, ordenes, cedulas, aranceles y ordenanzas expedidas para su gobierno y fomento. Madrid, en la imprenta de Benito Cano, 1787-1800. 45 v.

MADOZ, P. 1847: Diccionario geográfico-estadísticohistórico de España y sus posesiones de Ultramar, tomo I, Madrid: Est. Tipográfico-Literario Universal. Voz “Abánades”, (1847): 36-37.

MARTÍN GALÁN, M.M. 1983: "Brihuega y la fábrica de paños en el siglo XVIII". Estudios Geográficos 44, n 172-173, 469-498.

MARTÍN VISO, I. 2003: "Regadíos y molinos en la vega del Tajuña (siglos XII-XIII): Del control comunitario al domicilio señorial". En C. Segura (ed.) Agua y sistemas hidráulicos en la Edad 
Media Hispana, Asociación Cultural AlMudayna, Madrid: 133-162.

MEDINA DEL CERRO, L. 2000-2001: "Molinos de Guadalajara". Cuadernos de Etnología de Guadalajara 32-33, 155-248.

MÉNDEZ-CABEZA FUENTES, M. 1998: Los molinos de agua de la provincia de Toledo, Toledo : Instituto Provincial de Investigaciones y Estudios Toledanos, $271 \mathrm{p}$.

MIGUEL, J.C. de y SEGURA, C (dirs.) 1998: Agua e ingenios hidráulicos en el valle del Tajo: (de Estremera a Algodor entre los siglos XIII y XVIII). Madrid, Confederación Hidrográfica del Tajo, $231 \mathrm{p}$.

MIÑANO, S. de 1826: Diccionario GeográficoEstadístico de España y Portugal dedicado al rey Nuestro Señor. Tomo I. Madrid, Imprenta de Pierart-Perata.

RODRÍGUEZ MONTEOLIVA, F. 1989: “Los molinos de harina en la Alpujarra de Granada, durante los siglos XVI al XVIII. Léxico, etnografía e Historia", Actas del I Coloquio de Historia y Medio Físico: El Agua en zonas áridas: Arqueología e Historia, Almería, Instituto de Estudios Almerienses, 683 - 712.

RUIZ MONTEJO, I.; FRONTÓN SIMÓN, I. y PÉREZ CARRASCO, F.J. 1992: La herencia románica en Guadalajara. Toledo: Servicio de Publicaciones de la Junta de Comunidades de Castilla - La Mancha. Col. Patrimonio Histórico de Castilla - La Mancha, 5, 418 p. voz Abanades, pp. $255-260$.

ORTIZ GARCÍA, A, (ed.) 2002: Relaciones topográficas de la provincia de Guadalajara (2002). Aache Ediones. Guadalajara. $2^{\mathrm{a}}$ Ed., CD-ROM.

PAVÓN MALDONADO, B. 1984: Guadalajara medieval. Arte y Arqueología Árabe y Mudéjar. Madrid: CSIC, $230 \mathrm{p}$.

SÁNCHEZ FERRER, J. 1990: "Noticias documentales para el estudio y la localización de los batanes de la provincia de Albacete". Al-Basit. Revista de Estudios Albacetenses 26: 27-79.

SANTAMARÍA DE GRACIA, L. y ROHMER, E. 1989: "Colmenar Viejo: molinos y batanes en el tramo medio del Manzanares". En Los molinos: cultura y tecnología, coord. por Luis Vicente Elías Pastor: 311-316.

SEGURA GRAIÑO, C. 2003: "Sistemas de aprovisionamiento hidráulico e historia social". En C. Segura (coord.) Agua y sistemas hidráulicos en la Edad Media Hispana, Asociación Cultural AlMudayna, Madrid: 9-26.
SORROCHE CUERVA, M.A. 1999: “Arquitectura de la producción en la falda norte de Sierra Nevada: el molino. Características formales y sistemas constructivos". En Actas de las II Jornadas de Molinología (Tarrasa-La Pobla de Cérvoles, 30 de septiembre a 3 de octubre de 1998), Lérida: 189-199.

TABALES RODRIGUEZ, M.A. 2001: "Sevilla a fines del primer milenio. Breve aproximación arqueológica”. Actas del V Congreso de Arqueología Medieval Española, vol. II.: 599 - 607.

TABALES RODRÍGUEZ, M.A. 2001b: "Nuevas investigaciones en la Giralda. Excavaciones arqueológicas en la cara sur". Anuario Arqueológico de Andalucía 1998, III, vol. 2, 778 - 787.

TABALES RODRIGUEZ, M.A. 2001c: "Análisis arqueológico de paramentos. Algunas reflexiones referentes a las últimas actividades sobre inmuebles históricos en la ciudad de Sevilla". Actas del $\mathrm{V}^{\mathrm{o}}$ Congreso de Arqueología Medieval Española, vol. I.: $319-328$.

TABALES RODRÍGUEZ, M.A. 2001d: "El Hospital de las Cinco Llagas de Sevilla. Primera fase de estudios Arqueológicos. 1998". Anuario Arqueológico de Andalucía 1998, III, vol. 2, 751 - 768.

TABALES RODRIGUEZ, M.A. 2002: Sistema de análisis arqueológico de edificios históricos. Sevilla, Universidad de Sevilla, 280 p.

TABALES RODRIGUEZ, M.A. y ROMERO PAREDES, C. 2001: "La iglesia mudéjar de San Ana de Guadalcanal (Sevilla). Análisis constructivo". Actas del V Congreso de Arqueología Medieval Española, vol. II: $879-895$.

TABALES RODRIGUEZ, M.A. y ROMERO PAREDES, C. 2001b: "Investigaciones arqueológicas en la iglesia de Santa Ana de Guadalcanal”. Anuario Arqueológico de Andalucía 1996, III: 486 - 505.

TABALES RODRIGUEZ, M.A. POZO BLAZQUEZ, F. Y OLIVA ALONSO, D. 1999: Estudio arqueológico del Palacio de Conde de Ibarra 18, Sevilla. Anuario Arqueológico de Andalucía. 1995, III: 491 - 506.

TABALES RODRIGUEZ, M.A. et alii, 2001: "Análisis arqueológico del sector exterior oriental de la catedral de Sevilla". Anuario Arqueológico de Andalucía 1996, III: 393 - 404.

VALOR PIECHOTTA, M. 1989: "Molinos hidráulicos de Rodezno en el Aljarafe sevillano". En Actas del I Coloquio de Historia y Medio Físico. El Agua en zonas áridas: Arqueología e Historia. Almería, Instituto de Estudios Almerienses. Departamento de Historia: 739 - 748. 


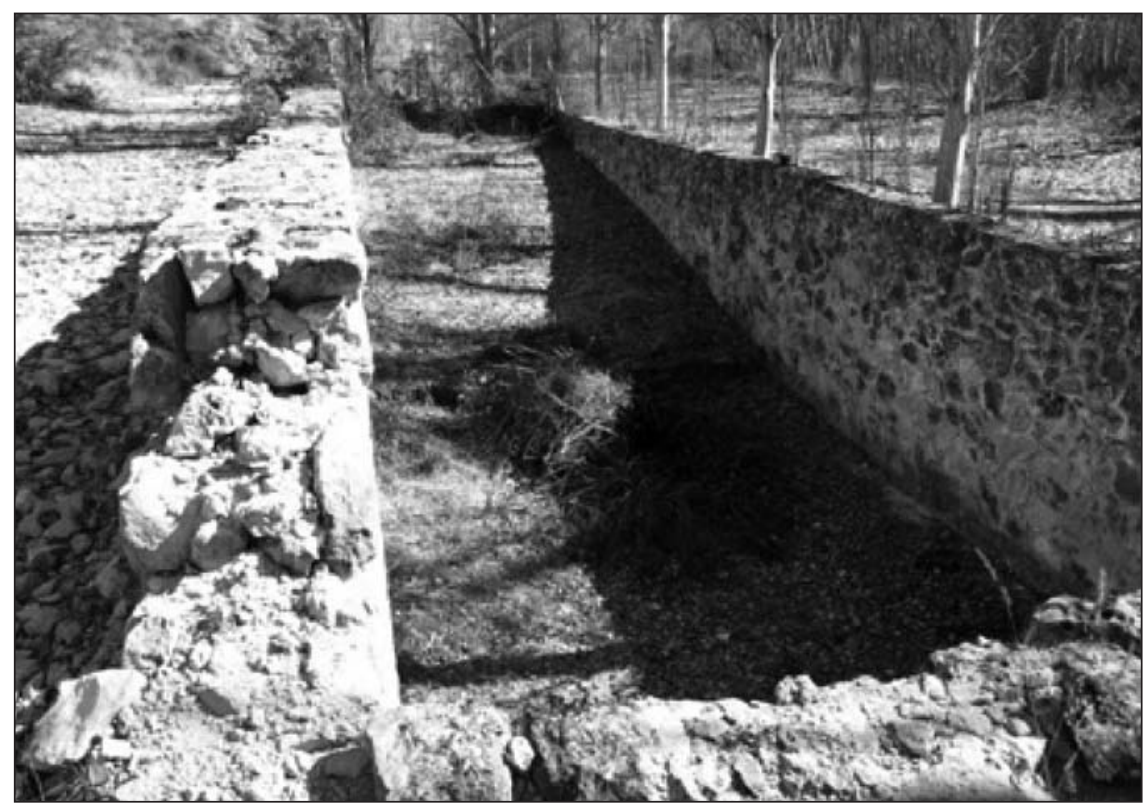

Figura 2.

Vista del caz aguas arriba

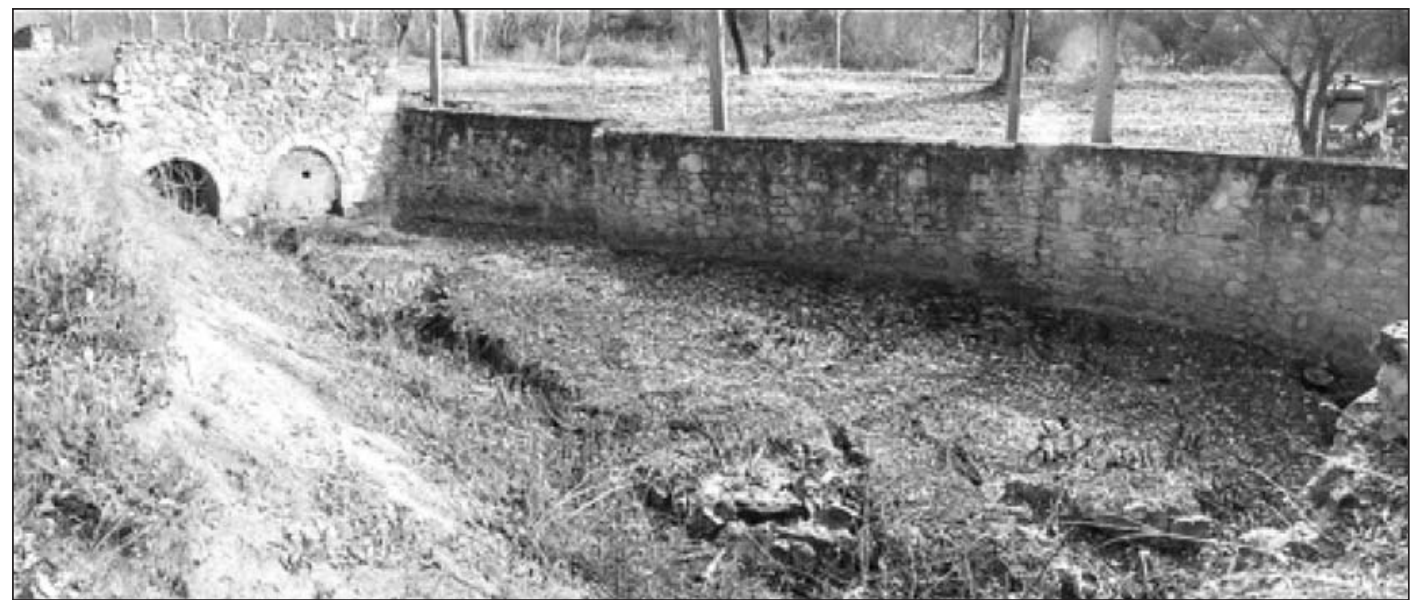

Figura 3. Vista del caz aguas abajo

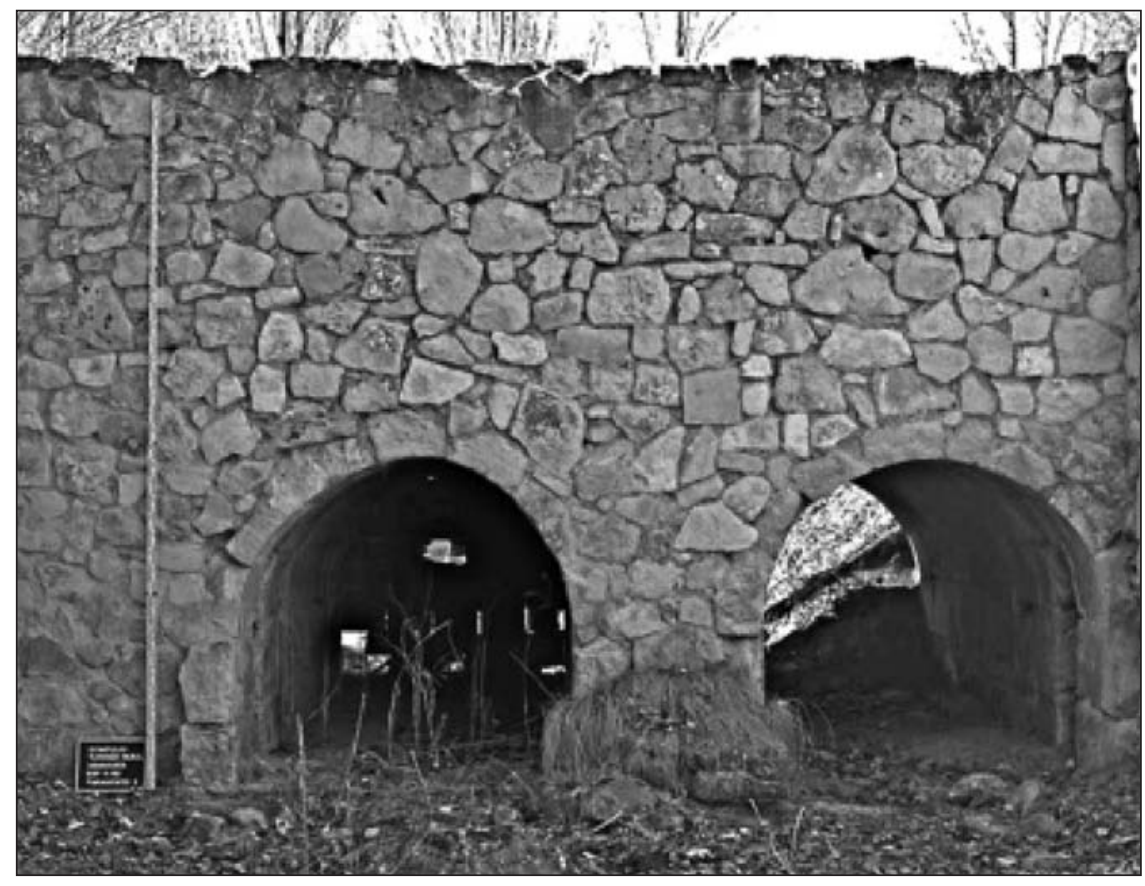

\section{Figura 4}

Paramento del batán aguas arriba. 


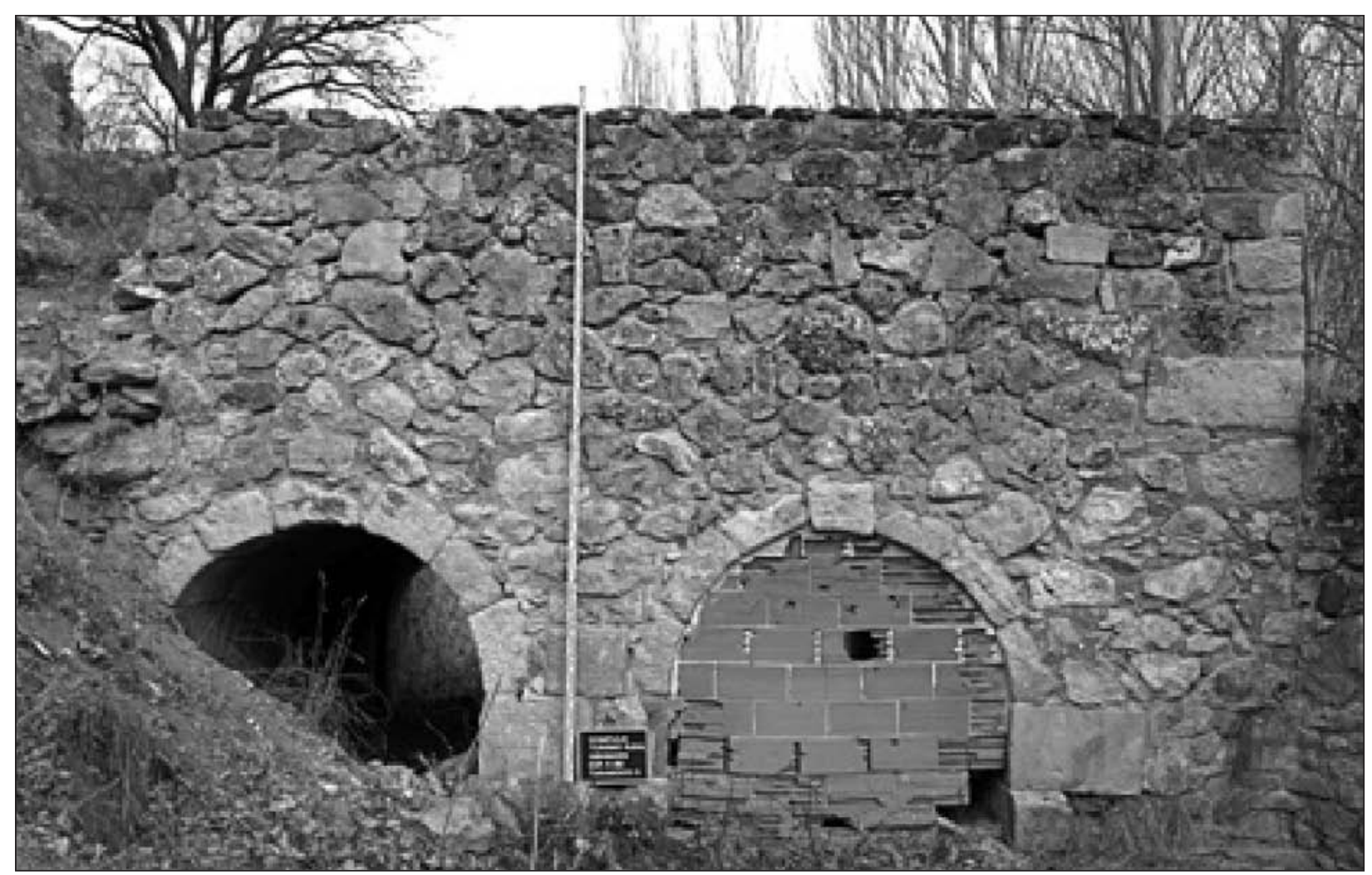

Figura 5. Paramento del batán aguas abajo

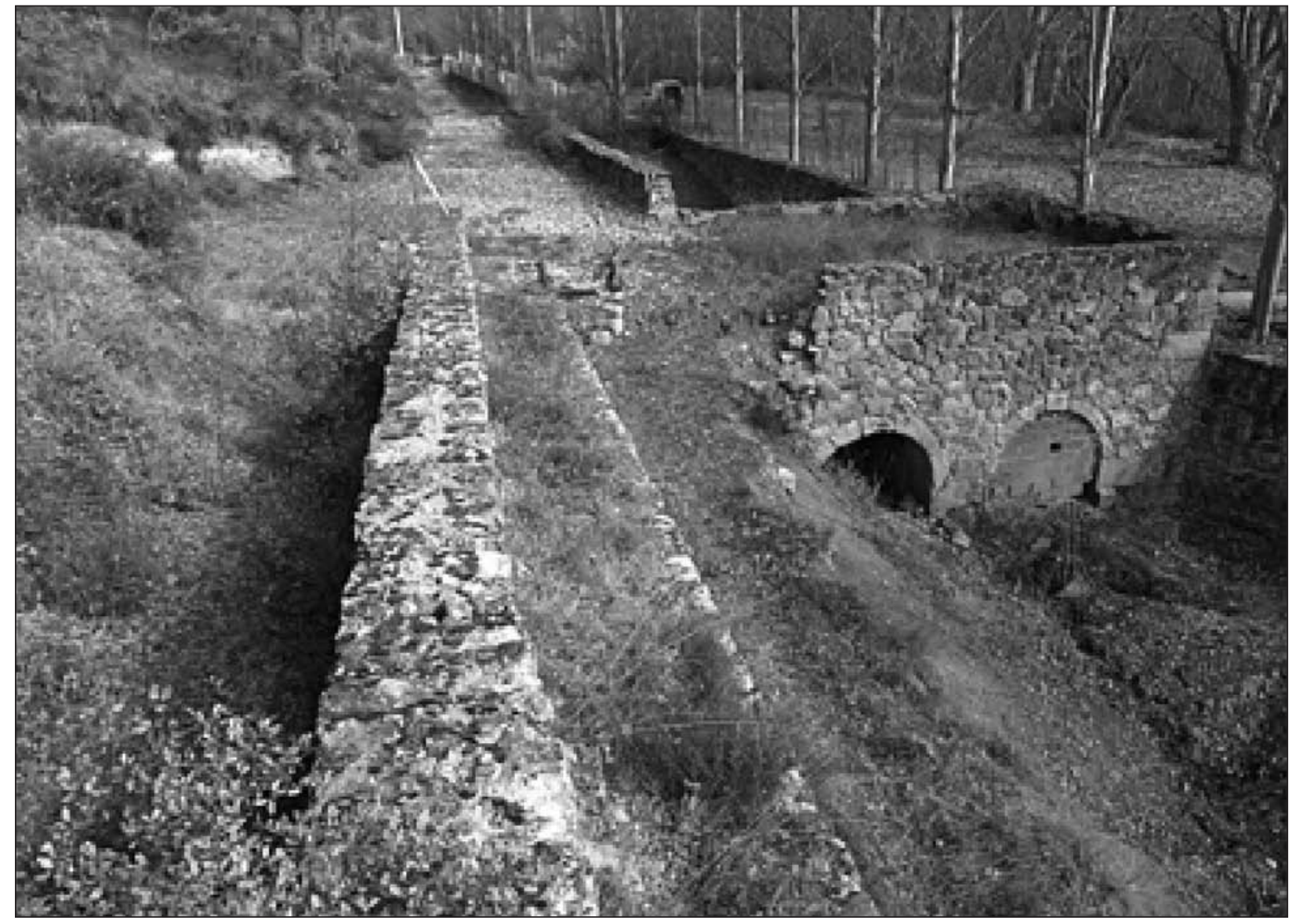

Figura 6. Vista del conjunto del batán. 


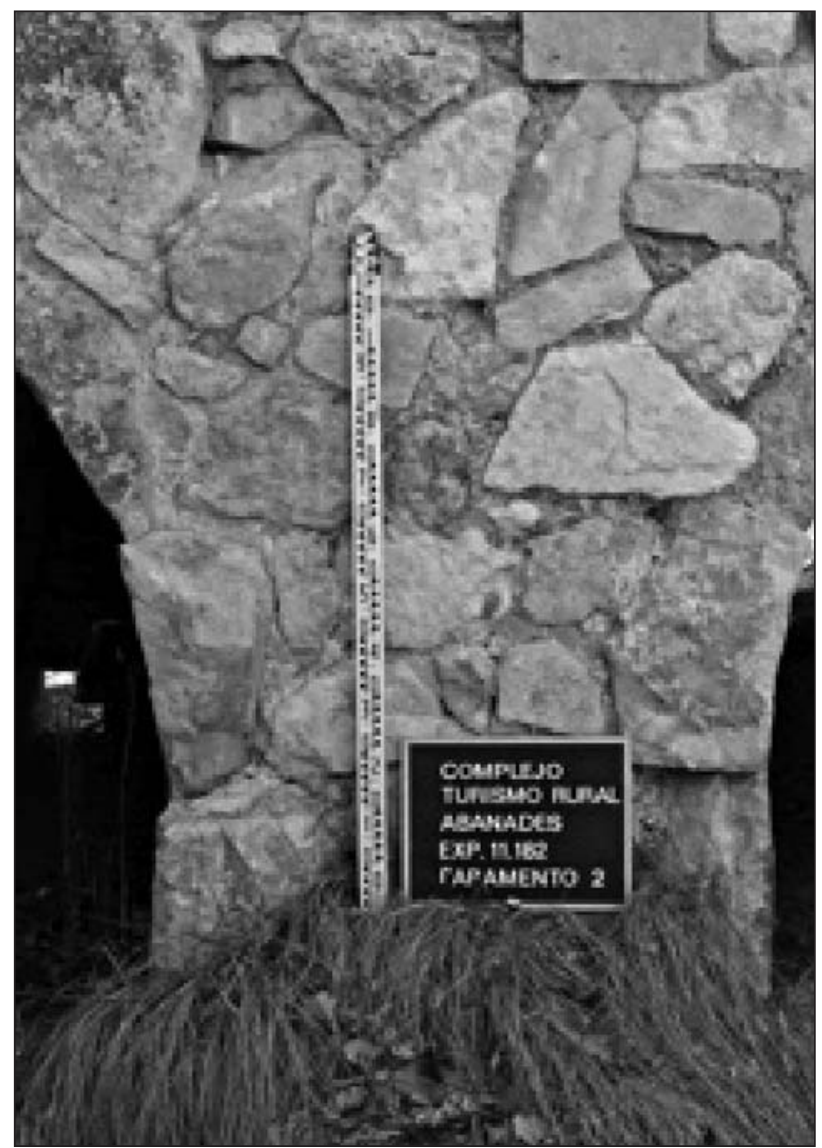

Figura 7 Detalle entre dos cárcavos, paramento aguas arriba.

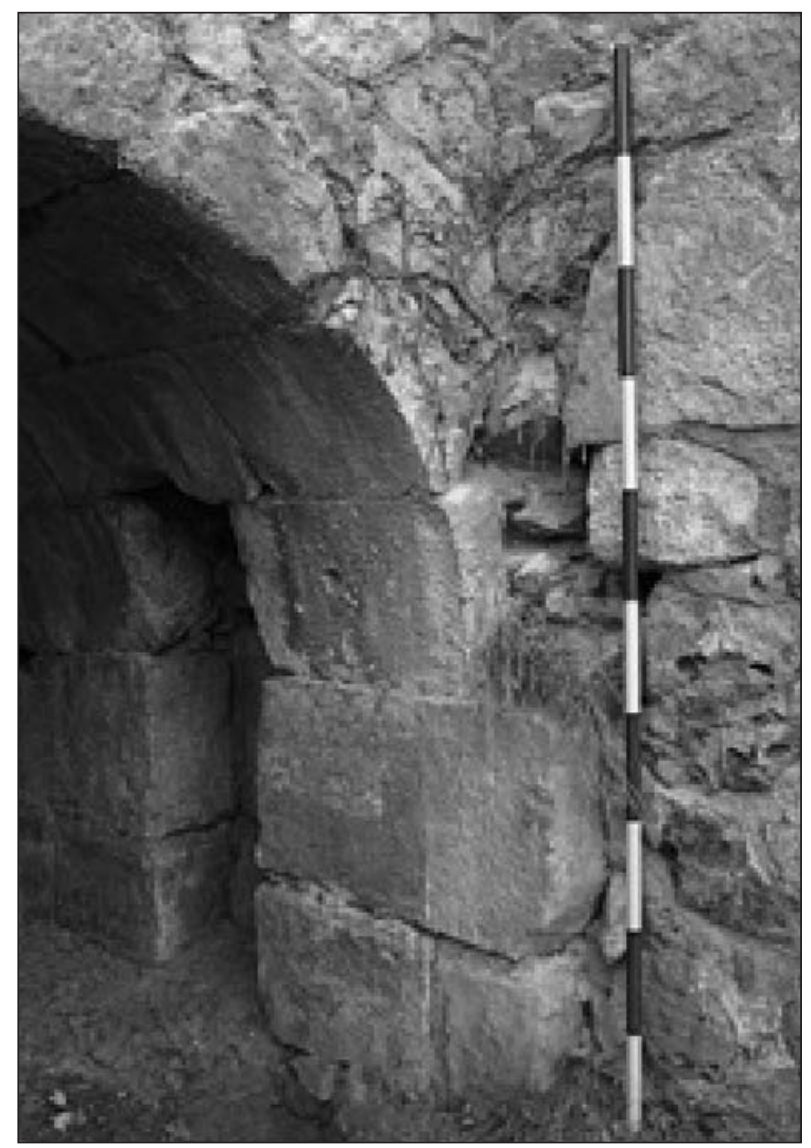

Figura 8. Detalle de la unión de paramentos

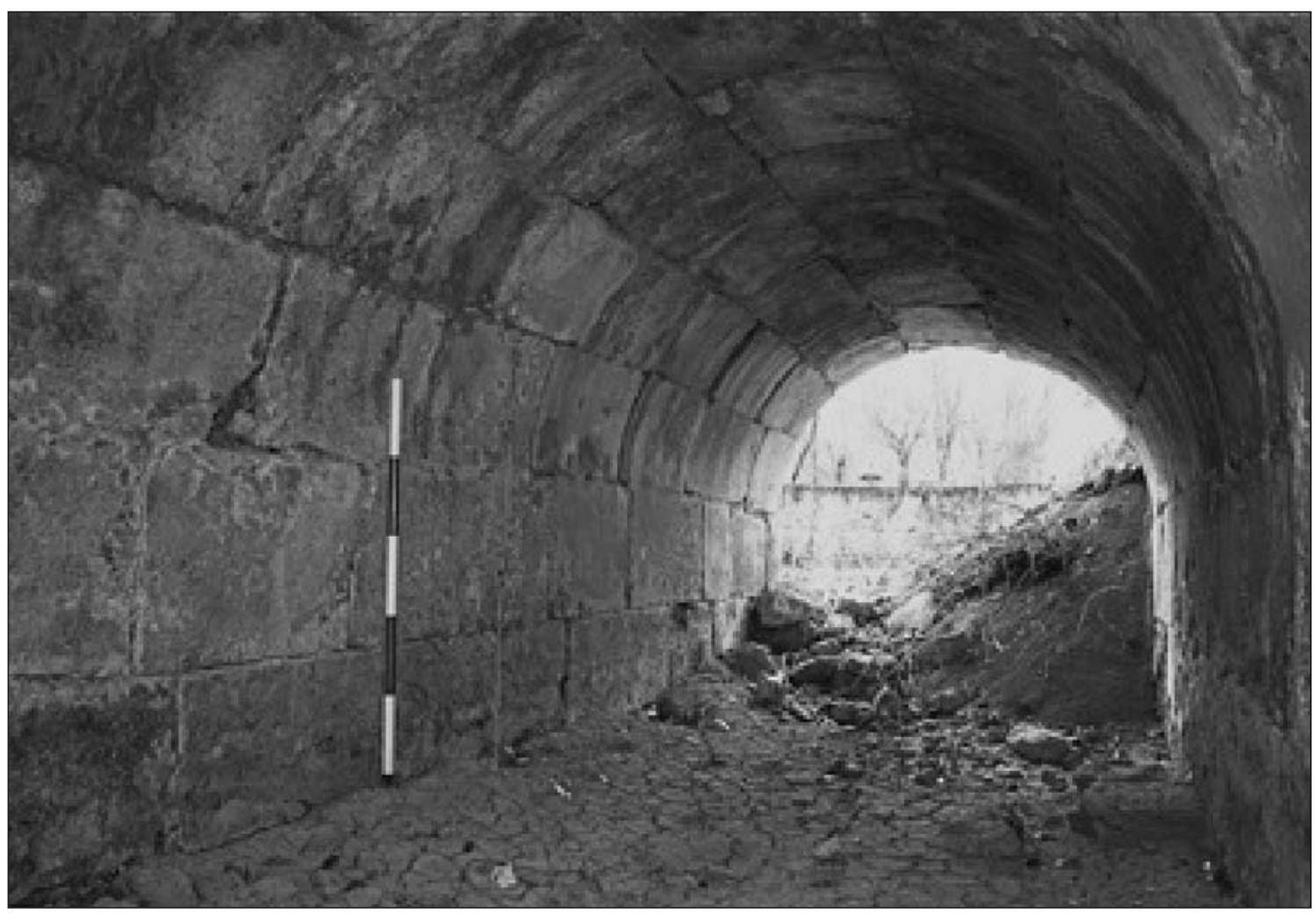

Figura 9 Cárcavo norte 


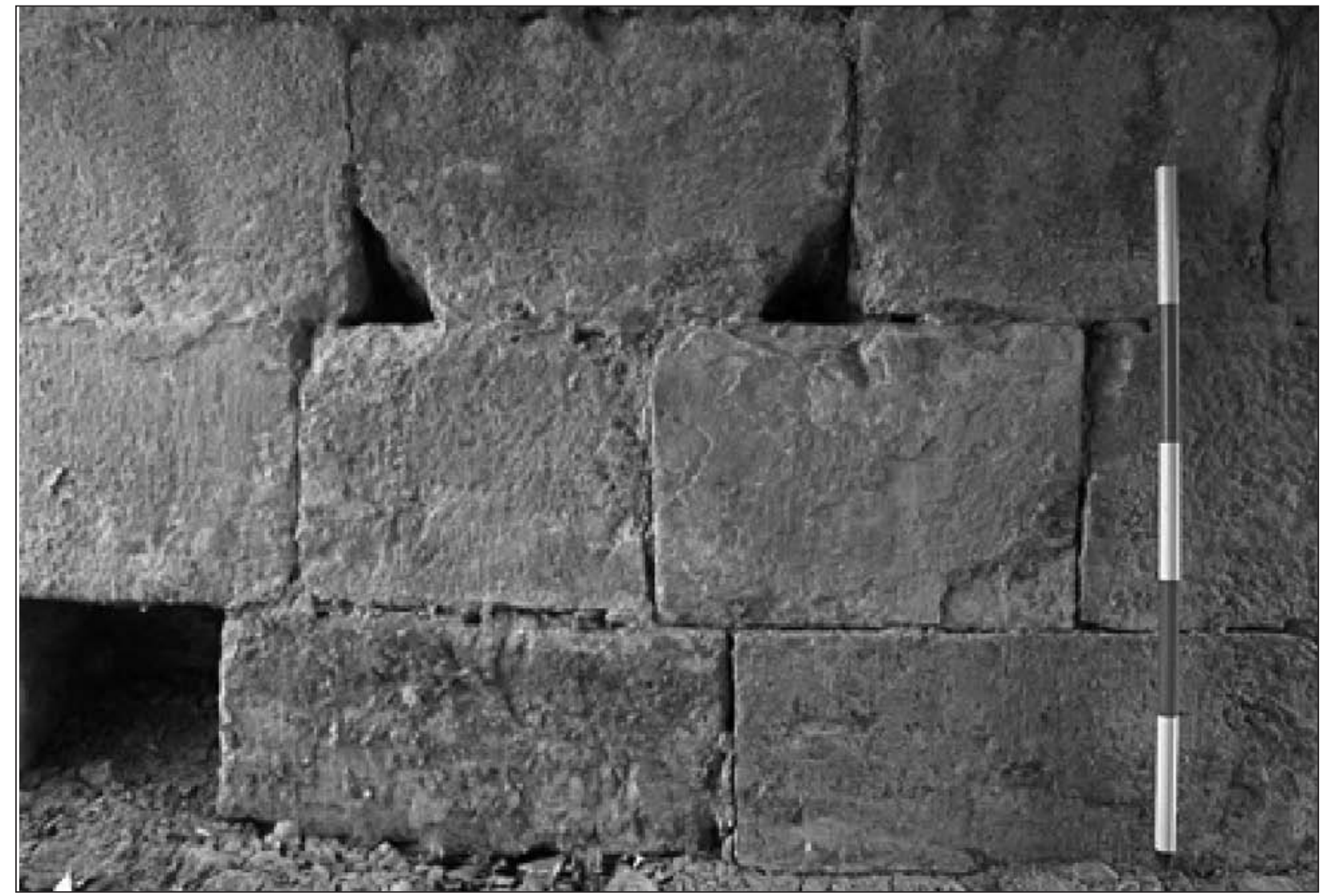

Figura 10. Detalle de paramento en cárcavo norte.

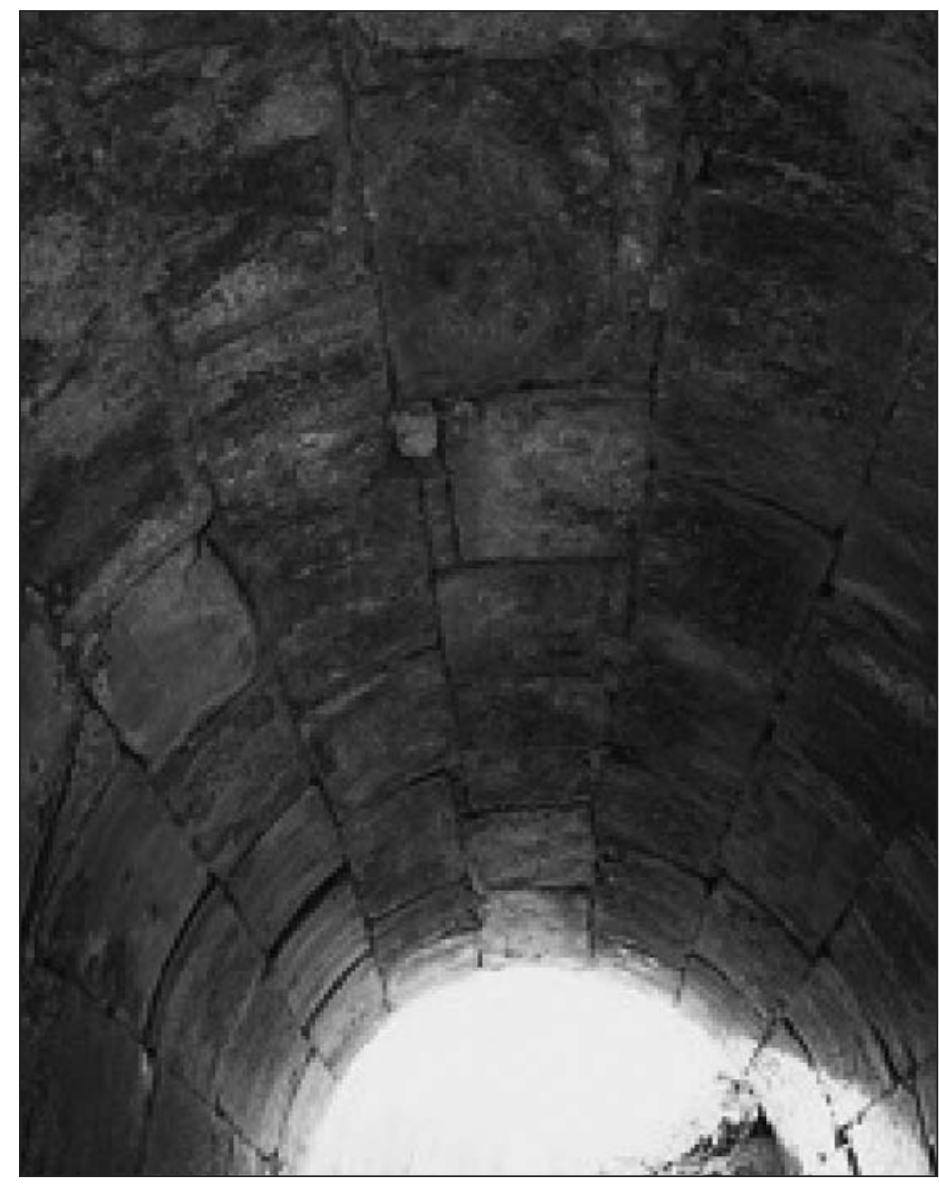

Figura 11. Detalle de la bóveda del cárcavo norte. 


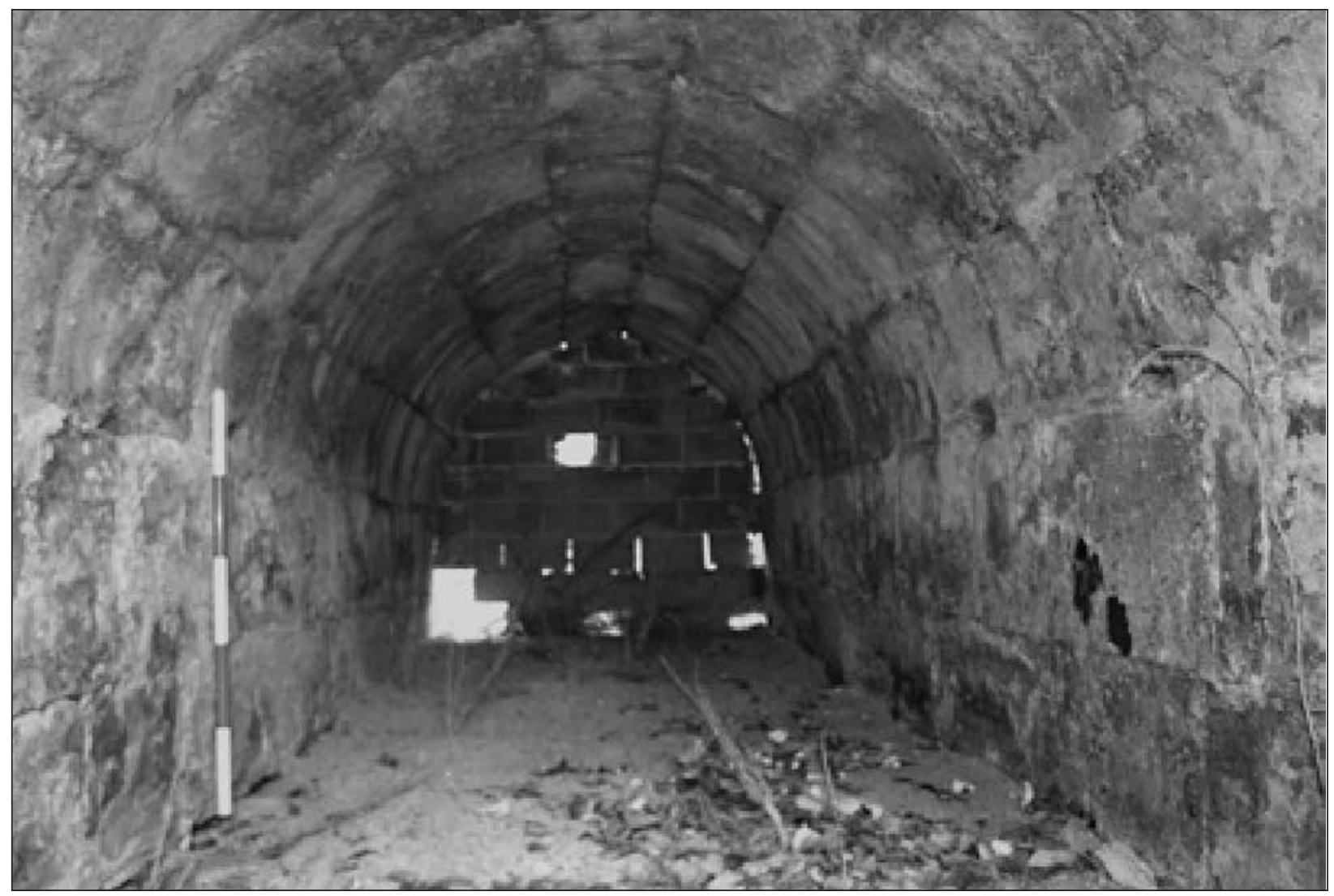

Figura 12. Cárcavo sur

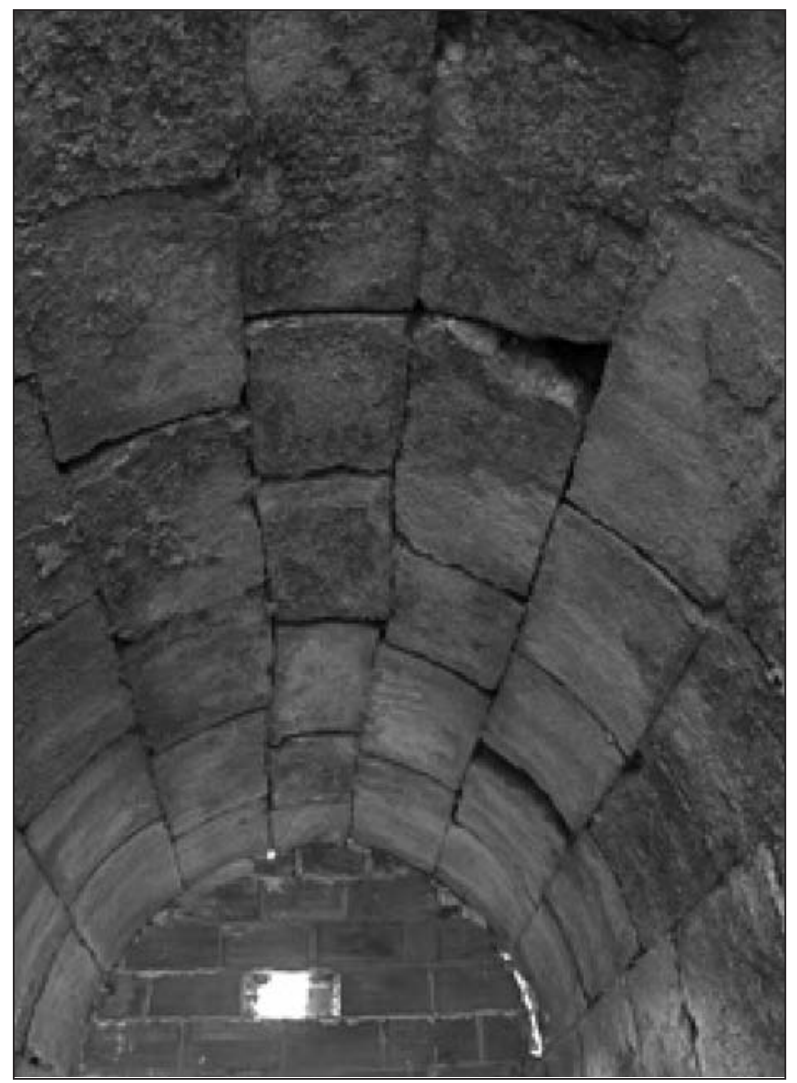

Figura 13. Detalle de la bóveda del cárcavo sur

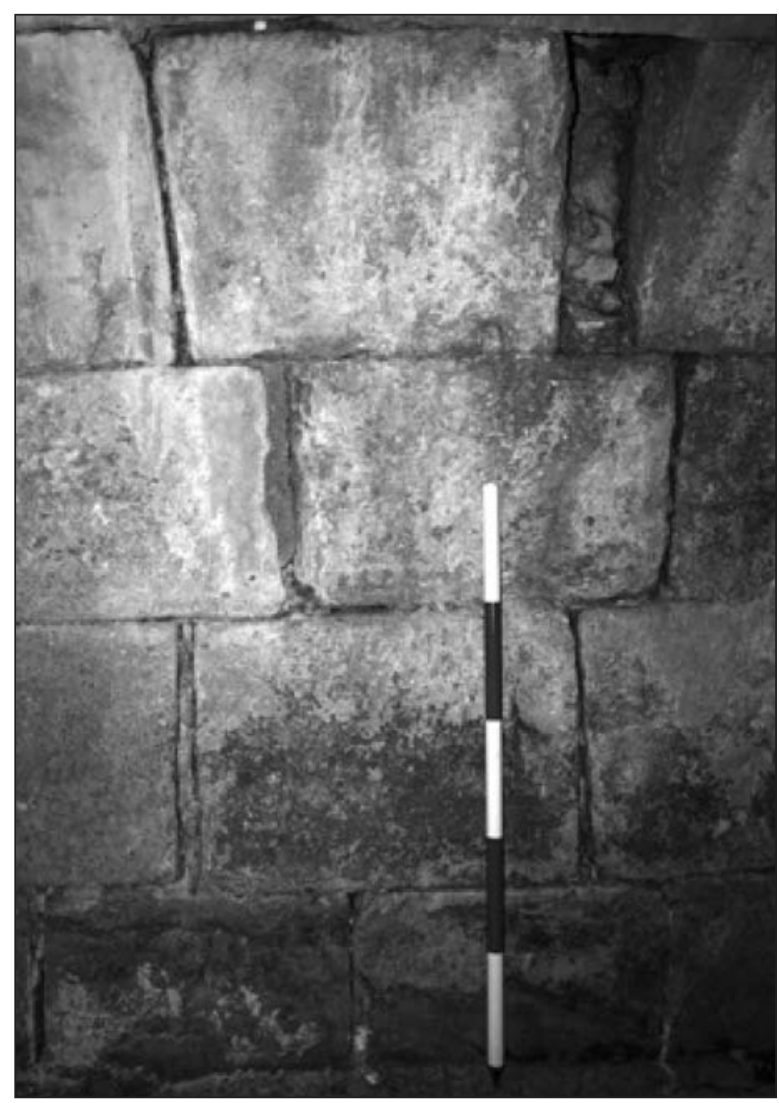

Figura 14. .- Detalle de paramento del cárcavo sur. 


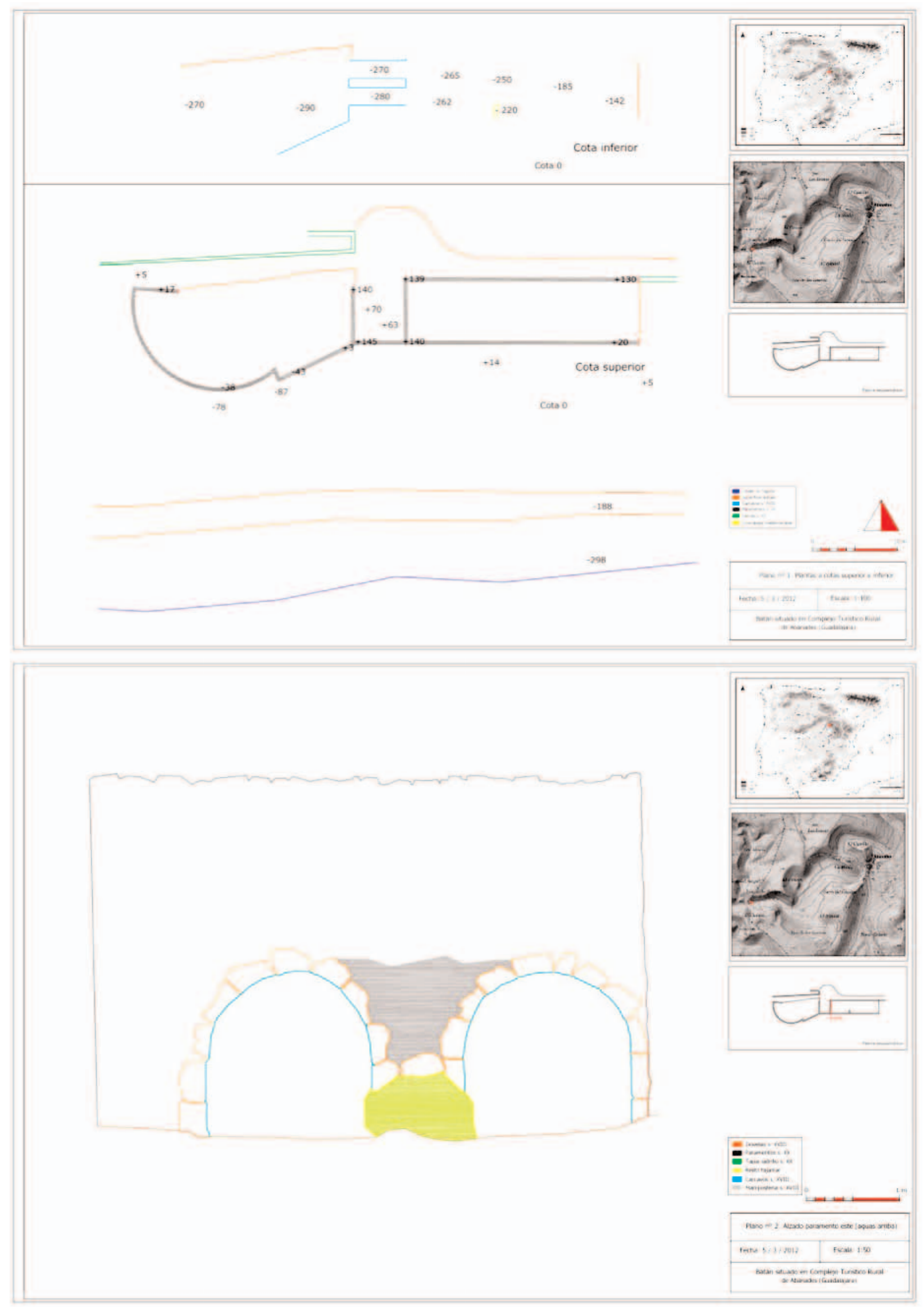

Figura 15. El batán de Abánades. Arqueología de la arquitectura en el alto Tajuña (Guadalajara) 